MICE Note-207

\title{
The Dimensions and Number of Turns for the Spectrometer Solenoids As-built compared to the Original Magnet Design
}

\author{
Michael A. Green and Steve P. Virostek \\ Lawrence Berkeley Laboratory, Berkeley CA 94720, USA
}

18 June 2008*

\begin{abstract}
The two tracker solenoids for MICE [1]-[3] as-built are different from the original design proposed by Wang NMR [4]. The Wang NMR design is in turn different from the magnet design proposed in the original MICE tracker magnet specification [5]. The two tracker solenoids where fabricated with niobium titanium conductor supplied to LBNL by Luvata under a specification written by LBNL [6]. This report compares the as-built tracker solenoids to the original Wang NMR design [4]. The as-built solenoid coils are thicker by 5 to 8 percent than called for the original design. This means that the current center is moved outward from 0.2 to 0.5 percent. In both tracker magnets, the thickness of end coil 2 was increased by 2-layers over the original design [5]. Thus, the current center for end coil 2 was moved outward by 0.7 percent. The number of turns per layer was underestimated in the original design from 2 to 4 percent. As a result, the current in each of the five tracker solenoid coils must be increased. In turn, the two as built tracker solenoids are compared to each other. In the ways that matter, the two tracker solenoids are nearly identical to each other. The largest difference between the two magnets that matters is a 0.05 percent change in the current in the center coil of the three coil set that forms the spectrometer solenoid. Since this is the largest variation that matters, it can be concluded that coils M1, coils M2, and the spectrometer solenoid can be connected in series without affecting the beam dynamics of MICE. This includes the two tuned end coils as well. The position of the coils within the cryostats vacuum vessel appears to be acceptable.
\end{abstract}

\section{TABLE OF CONTENTS}

$\begin{array}{lr}\text { Abstract } & 1 . \\ \text { The Basic Design Parameters for the MICE Tracker Solenoids } & 2 . \\ \text { A Comparison of Tracker Solenoid Parameters to the Vendor Design Parameters } & 4 . \\ \text { A Comparison of the Two Tracker Solenoids to Each Other } & 7 . \\ \text { Errors in the Placement of the Two Cold Masses in their Vacuum Vessels } & 10 . \\ \text { Some Concluding Comments } & 13 . \\ \text { Acknowledgements } & 14 . \\ \text { References } & 14 .\end{array}$

* Last revision 18 June 2008 


\section{The Basic Design Parameters for the MICE Tracker Solenoids}

A reference design for the tracker solenoids shown in Table 1 was given in the tracker magnet specification [5]. The reference design was based on using a superconductor that insulated matrix dimensions of 1.0 by $1.65 \mathrm{~mm}$. The minimum acceptable critical current for the superconductor was set at $760 \mathrm{~A}$ at $4.22 \mathrm{~K}$ and 5.0 T. See Reference [6].

Table 1. The Basic Parameters of the Spectrometer Solenoid

\begin{tabular}{|c|c|c|c|c|c|}
\hline Parameter & Match 1 & Match 2 & End 1 & Center & End 2 \\
\hline Inner Coil Radius (mm)+ & 258 & 258 & 258 & 258 & 258 \\
\hline Coil Thickness (mm) & 46.2 & 30.8 & 61.6 & 22.0 & 68.2 \\
\hline Coil Length $(\mathrm{mm})$ & 198 & 197 & 110 & 1294 & 110 \\
\hline Current Centre Axial Position* (mm) & $124 \pm 1$ & $564 \pm 1$ & $964 \pm 1$ & $1714 \pm 1$ & $2464 \pm 1$ \\
\hline Current Centre Radial Position\# (mm)+ & 281.1 & 273.4 & 288.8 & 269.0 & 292.1 \\
\hline Coil Average $\mathrm{J}\left(\mathrm{A} \mathrm{mm}^{-2}\right)$ & 118.04 & 138.28 & 136.80 & 146.90 & 142.49 \\
\hline Number of layers per Coil & 48 & 28 & 56 & 20 & 62 \\
\hline Number of Turns per Layer & $120 \pm 2$ & $119 \pm 2$ & $66 \pm 1$ & $784 \pm 10$ & $66 \pm 1$ \\
\hline Design Current $(\mathrm{A})^{* *}$ & 223.3 & 271.2 & 249.5 & 265.9 & 265.2 \\
\hline Coil Self Inductance $(\mathrm{H})^{\wedge}$ & 17.1 & 5.0 & 9.6 & 41.6 & 11.4 \\
\hline Coil Stored Energy $(\mathrm{MJ})^{* *}$ & 0.47 & 0.20 & 0.30 & 1.49 & 0.40 \\
\hline Peak Field in Coil $(\mathrm{T})^{* *}$ & 4.7 & 2.42 & 5.61 & 4.02 & 5.62 \\
\hline Temperature Margin at $4.2 \mathrm{~K}(\mathrm{~K})^{* *}$ & $\sim 2.0$ & $\sim 2.5$ & $\sim 1.9$ & $\sim 2.3$ & $\sim 1.7$ \\
\hline Conductor Length per Coil (m) & 8910 & 5730 & 7220 & 25720 & 7910 \\
\hline Estimated Coil Mass (kg) & 133 & 67 & 89 & 347 & 98 \\
\hline Total Conductor Length for Magnet (m) & \multicolumn{5}{|c|}{55,490} \\
\hline Cold Mass Inner Diameter $(\mathrm{mm})$ & \multicolumn{5}{|c|}{490} \\
\hline Cold Mass Outer Diameter (mm) & \multicolumn{5}{|c|}{690} \\
\hline Cold Mass Length $(\mathrm{mm})$ & \multicolumn{5}{|c|}{2544} \\
\hline Insulation Thickness, Mandrel (mm) & \multicolumn{5}{|c|}{$>0.75$} \\
\hline Min. Coil-to-Ground Clear Path (mm) & \multicolumn{5}{|c|}{5} \\
\hline Vacuum Vessel Outer Diameter (mm) & \multicolumn{5}{|c|}{$1404 \pm 3$} \\
\hline Magnet Warm Bore $(\mathrm{mm})$ & \multicolumn{5}{|c|}{$401 \pm 3$} \\
\hline Magnet Cryostat Length $(\mathrm{mm})$ & \multicolumn{5}{|c|}{$2735 \pm 1$} \\
\hline Cryostat End Wall-to-Vessel Flange (mm) & \multicolumn{5}{|c|}{$259 \pm 1$} \\
\hline Total Magnet Cold Mass (kg) & \multicolumn{5}{|c|}{$\sim 1390$} \\
\hline Copper Shield and Intercepts Mass (kg) & \multicolumn{5}{|c|}{$\sim 290$} \\
\hline Vacuum Vessel and Cooler Mass (kg) & \multicolumn{5}{|c|}{$\sim 1990$} \\
\hline PMT Iron Shield Mass (kg) & \multicolumn{5}{|c|}{$\sim 1240$} \\
\hline Total Spectrometer Solenoid Mass (kg) & \multicolumn{5}{|c|}{$\sim 4910$ (with iron shield) } \\
\hline
\end{tabular}

$+\quad$ The coil radius my be adjusted by the subcontractor by up to $+5 \mathrm{~mm}$

* Axial dimensions are from the match coil end of the cold mass.

\# Radial dimensions are from the magnet axis

** For the standard (Case 1) with $p=200 \mathrm{MeV} / \mathrm{c}$ and $\beta=42 \mathrm{~cm}$ based on the $300 \mathrm{~K}$ dimensions of the coils

$\wedge \quad$ The self-inductance of the two end coils and the centre coil in series $=77 \mathrm{H}$. 
The vendor for the tracker solenoid (Wang NMR) came back with his proposal as to how the tracker solenoid. The design proposed by the vendor is shown in Table 2 [4]. The design proposed by the vendor called for the same number of layers and turns as in the reference design given in Table 1. The coil length for the vendor design is somewhat longer than the reference design. The vendor proposal called for superconducting coils that were thinner than the reference design given in Table 1. The currents given in Table 2 are the worst-case currents expected when the tracker solenoid is run for muons with an average momentum of $240 \mathrm{MeV} / \mathrm{c}$ and a $\beta$ at the center of the absorbers (in the AFC modules) of $420 \mathrm{~mm}$. The magnetic induction within the tracker region (within the center coil) is designed to $4 \mathrm{~T}$ with a design field uniformity of \pm 0.3 percent over a region that is $1000 \mathrm{~mm}$ long and $300 \mathrm{~mm}$ in diameter around the center of the center coil of the tracker solenoid. The design calls for end coil 1, the center coil and end coil 2 being connected in series. Correction currents are put into end coil 1 and end coil 2 in order to achieve the desired field uniformity within the tracker volume.

Table 2. The Nominal Design Parameters for the MICE Tracker Solenoid that was proposed by the Tracker Solenoid Vendor (Wang NMR)

\begin{tabular}{lccccc}
\hline \hline Parameter & Match 1 & Match 2 & End 1 & Center & End 2 \\
\hline Inner Coil Radius (mm) & 258.0 & 258.0 & 258.0 & 258.0 & 258.0 \\
Coil Thickness (mm) & 44.6 & 29.8 & 59.6 & 21.3 & 63.9 \\
Coil Length (mm) & 201.2 & 199.5 & 110.6 & 1314.3 & 110.6 \\
Current Center Axial Position* (mm) & 124.00 & 564.00 & 964.00 & 1714.00 & 2464.00 \\
Current Center Radial Position* (mm) & 280.3 & 272.9 & 287.8 & 268.7 & 289.9 \\
Coil Average J (A mm ${ }^{-2}$ ) & 142.19 & 152.62 & 127.05 & 153.38 & 141.95 \\
Number of layers per Coil & 42 & 28 & 56 & 20 & 60 \\
Total Number of Turns per Layer & 120 & 119 & 66 & 784 & 66 \\
Total Number of Turns per Coil & 5040 & 3332 & 3696 & 15680 & 3960 \\
Design Current (A)** & 253.8 & 273.6 & 226.6 & 269.9 & 240.7 \\
Coil Self Inductance (H) & 13.0 & 5.4 & 9.5 & 41.4 & 11.1 \\
Coil Stored Energy $(\mathrm{MJ})^{* *}$ & 0.42 & 0.20 & 0.26 & 1.54 & 0.32 \\
Peak Field in Coil (T)** & 5.30 & 4.32 & 5.68 & 4.24 & 5.86 \\
Temperature Margin at 4.2 K (K)** & $\sim 1.7$ & $\sim 1.9$ & $\sim 1.6$ & $\sim 2.0$ & $\sim 1.5$ \\
\hline
\end{tabular}

* $\quad$ Based on $Z=0$ is at the match coil end of the magnet cold mass. (The center of MICE in these coordinates is at $\mathrm{Z}=-3487 \mathrm{~mm}$.) $\mathrm{R}=0$ is the axis of the magnet (the MICE axis).

** This is at the maximum design current, which is based on the worst-case currents for the five coils.

$\wedge \quad$ The inductance of the two end coils and the center coil in series is about $77 \mathrm{H}$.

There are a number of differences between the reference design (Table 1) and the design proposed by the vendor (Table 2). For example, the peak field in the coils and the temperature margin is different for the reference design than the design proposed by the vendor. The reference design is based on a particular case for MICE $(p=200 \mathrm{MeV} / \mathrm{c}$ and $\beta=420 \mathrm{~mm})$ that has a lower coil peak field and a higher temperature margin. The design shown in Table 2 is based on worst-case calculations by the vendor. As a result, the peak field in the windings is a little higher for the vendor proposal (Table 2) as compared to the reference design (Table 1). The higher peak field in the windings in the vendor proposal results in lower temperature margin. Since Table 2 is considered to be a worst case, the temperature margins given are considered to be adequate for MICE operating in all of its projected operating modes. The tracker solenoid coils have higher temperature margins than any of the other superconducting magnets in MICE. 


\section{A Comparison of Tracker Solenoid Parameters to the Vendor Design Parameters}

The mandrels for the MICE tracker solenoids were machined from a single aluminum forging that was eight and a half feet $(\sim 2600 \mathrm{~mm})$ long and 28 inches $(711 \mathrm{~mm})$ in diameter. The final machined length for the mandrel was $2544 \mathrm{~mm}$ at room temperature. The mandrel inner bore was machined to $490 \mathrm{~mm}$. The mandrel was machined on the outside and the slots for the five coils were machined on the outside of the mandrel. A partially machined tracker solenoid mandrel is shown in Figure 1. The coil grooves shown in Figure 1 are know to an accuracy of $25 \mu \mathrm{m}$ as compared to the end of the aluminum mandrel (the end of the cold mass). The ground plane insulation was installed after machining. As a result, the axial position of the coil current center with respect to the end of the cold mass is known to better than $\pm 50 \mu \mathrm{m}$.

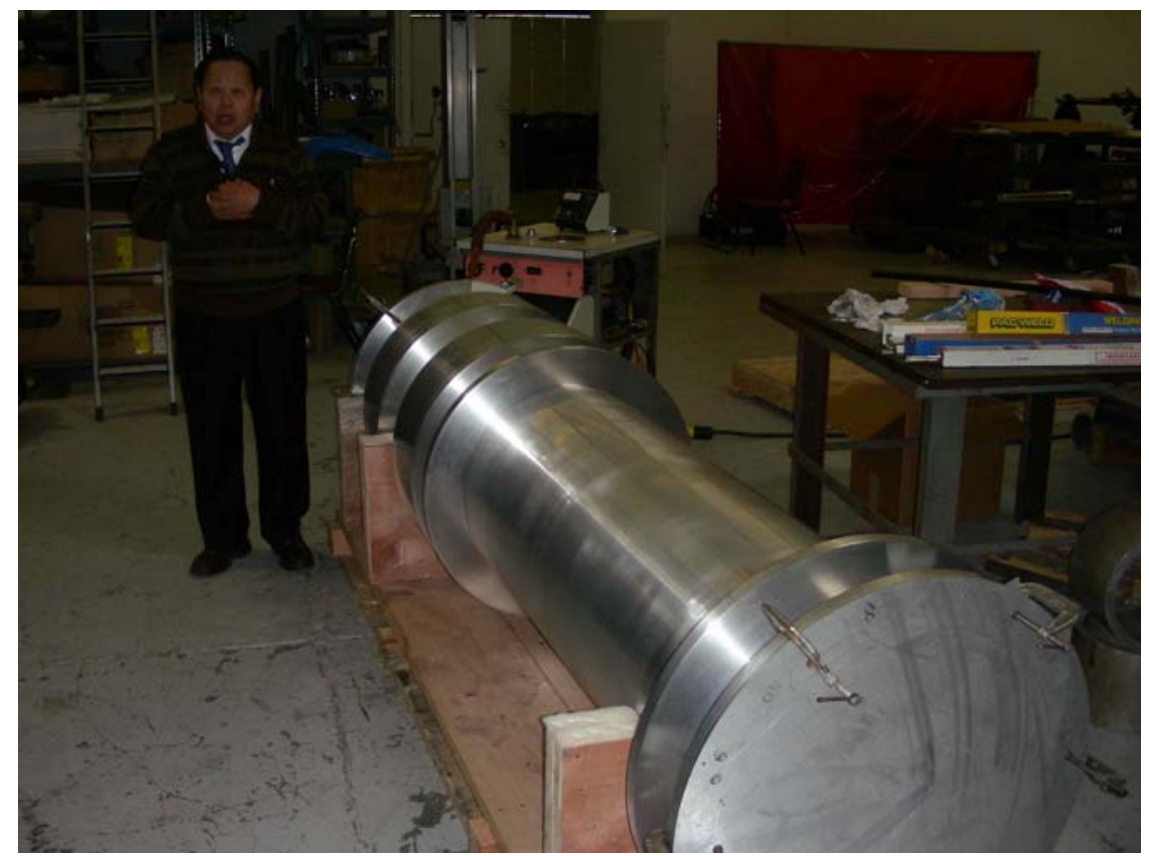

Figure 1. Tracker Magnet Mandrel External Machining (Note: the mandrel has not been machined in the bore.)

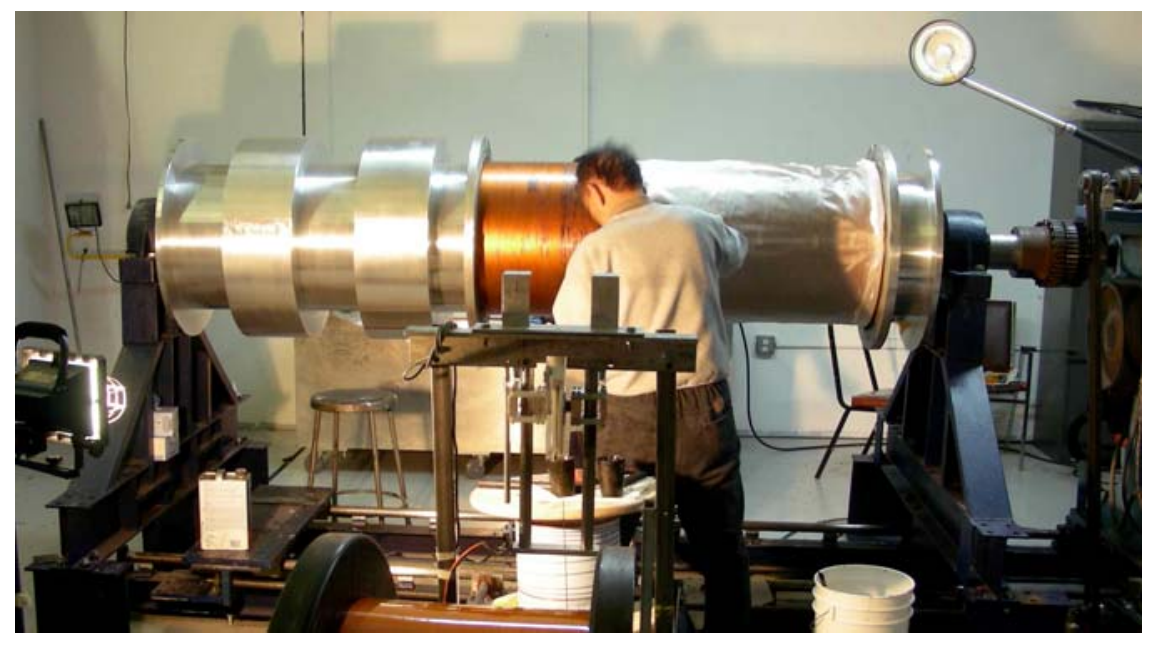

Figure 2. Winding the Center Spectrometer Coil of Tracker Magnet 1 
The winding of the center coil of magnet number 1 is shown in Figure 2. For both tracker magnets, the first wound was the center coil for the spectrometer solenoid set. Table 3 shows the actual as wound dimensions of the magnet coils for tracker magnet 1 . Table 4 compares the parameters shown in Table 3 with the vendor design shown in Table 2. The parameters shown in Table 4 are the parameters shown in Table 3 minus the parameters shown in Table 2.

Table 3. The As Built Dimensions and Turns for Tracker Solenoid Number 1

\begin{tabular}{lccccc}
\hline \hline Parameter & Match 1 & Match 2 & End 1 & Center & End 2 \\
\hline Inner Coil Radius (mm) & 258 & 258 & 258 & 258 & 258 \\
Coil Thickness (mm) & 46.483 & 30.608 & 61.638 & 22.416 & 68.220 \\
Coil Length (mm) & 201.268 & 199.492 & 110.642 & 1314.30 & 110.642 \\
Current Center Axial Position* (mm) & 124.00 & 564.00 & 964.00 & 1714.00 & 2464.00 \\
Current Center Radial Position* (mm) & 281.242 & 273.304 & 288.819 & 269.208 & 292.110 \\
Coil Average J (A mm ${ }^{-2}$ ) & 136.73 & 149.300 & 122.81 & 145.74 & 126.28 \\
Number of layers per Coil & 42 & 28 & 56 & 20 & 62 \\
Total Number of Turns per Coil & 115 & 114 & 64 & $766-768$ & 64 \\
Total Number of Turns & 4830 & 3192 & 3584 & 15352 & 3968 \\
Design Current (A)** & 264.83 & 285.60 & 233.68 & 275.67 & 240.21 \\
Coil Self Inductance (H)^ & 12.0 & 5.0 & 9.0 & 39.9 & 11.3 \\
Coil Stored Energy (MJ)** & 0.42 & 0.20 & 0.26 & 1.55 & 0.32 \\
Peak Field in Coil (T)** & 5.30 & 4.32 & 5.68 & 4.24 & 5.86 \\
Temperature Margin at 4.2 K (K)** & $\sim 1.6$ & $\sim 1.8$ & $\sim 1.5$ & $\sim 2.0$ & $\sim 1.5$ \\
\hline
\end{tabular}

* Based on $\mathrm{Z}=0$ is at the match coil end of the magnet cold mass. (The center of MICE in these coordinates is at $\mathrm{Z}=-3487 \mathrm{~mm}$.) $\mathrm{R}=0$ is the axis of the magnet (the MICE axis).

** This is at the maximum design current, which is based on the worst-case currents for the five coils.

$\wedge \quad$ The inductance of the two end coils and the center coil in series is about $74 \mathrm{H}$.

Table 4. Changes in As Built Dimensions and Turns for Tracker Solenoid Number 1 Compared to the Magnet Design shown in Table 2

\begin{tabular}{lccccc}
\hline \hline Parameter & Match 1 & Match 2 & End 1 & Center & End 2 \\
\hline Inner Coil Radius (mm) & $< \pm 0.05$ & $< \pm 0.05$ & $< \pm 0.05$ & $< \pm 0.05$ & $< \pm 0.05$ \\
Coil Thickness (mm) & +1.883 & +0.808 & +2.038 & +1.116 & +4.320 \\
Coil Length (mm) & 0.068 & -0.008 & +0.042 & -0.001 & +0.042 \\
Current Center Axial Position* (mm) & \pm 0.05 & \pm 0.05 & \pm 0.05 & \pm 0.05 & \pm 0.05 \\
Current Center Radial Position* (mm) & +0.942 & +0.404 & +1.019 & +0.558 & +2.160 \\
Coil Average J (A mm ${ }^{-2}$ ) & -5.46 & -3.32 & -4.24 & -7.64 & -15.67 \\
Number of layers per Coil & 0 & 0 & 0 & 0 & +2 \\
Number of Turns per Layer & -5 & -5 & -2 & -18 to -16 & -2 \\
Total Number of Turns & -210 & -140 & -188 & -328 & +8 \\
Design Current (A)* & +11.03 & +12.00 & +7.08 & +5.77 & -0.49 \\
Coil Self Inductance (H)^ & -1.0 & -0.4 & -0.5 & -1.5 & +0.2 \\
Coil Stored Energy (MJ)* & $\sim 0.00$ & $\sim 0.00$ & $\sim 0.00$ & $\sim+0.01$ & $\sim 0.00$ \\
Peak Field in Coil (T)* & $\sim 0.0$ & $\sim 0.0$ & $\sim 0.0$ & $\sim 0.0$ & $\sim 0.0$ \\
Temperature Margin at 4.2 K (K)* & $\sim-0.1$ & $\sim-0.1$ & $\sim-0.1$ & $\sim 0.0$ & $\sim 0.0$ \\
\hline
\end{tabular}

* This change is at the coil maximum design current, which is based on the worst-case currents for the five coils.

$\wedge \quad$ The change in inductance of the two end coils and the center coil in series is about $-3 \mathrm{H}$. 
When on looks at Table 4, one can see that the inner radius of the coils in tracker magnet 1 is the same (within $\pm 50 \mu \mathrm{m}$ ) as the design proposed by the vendor. The design proposed by the vendor has a higher turns density than the vendor actually wound in the magnet. Each coil layer is thicker than anticipated and there are fewer turns per coil layer than anticipated. As a result, the magnet coils are thicker with fewer turns. The coil center in radial direction is larger by about 0.16 percent to 0.68 percent. The current center in the axial direction is accurate (with respect to the end of the cold mass) to about $\pm 0.05 \mathrm{~mm}$. The design current for all of coils, except for end coil 2, is larger than the value called for in Table 2. The decision was made add two layers to end coil 2. Because the number turns per changed, the self-inductance of magnet coils changed accordingly. There is very little change in the magnet stored-energy, the coil peak field, and the coil temperature margin at $4.2 \mathrm{~K}$ between the magnet as built (Table 3 ) and the magnet as designed (Table 2).

Figure 3 shows tracker magnet 2 after all five coils have been wound and banded. Figure 4 shows tracker magnet 1 after the magnet cold mass has been closed and welded. Figure 4 shows the appearance of the finished cold mass, before it is insulated with MLI. The space between the shell and the coils is filled with liquid helium.

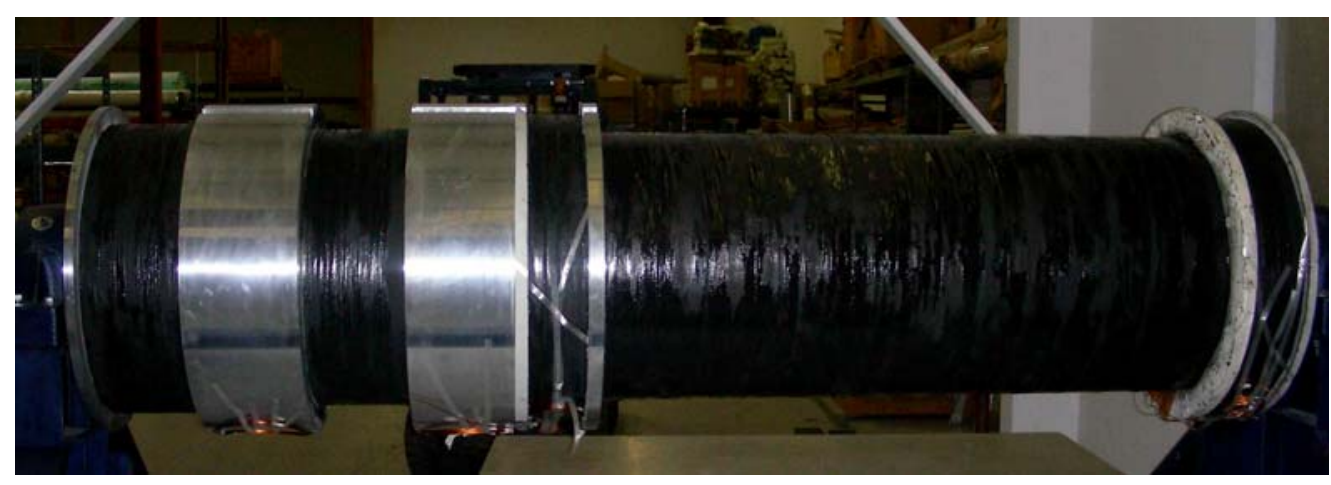

Figure 3. Tracker Magnet Fully Wound and Banded before the Cold Mass is closed

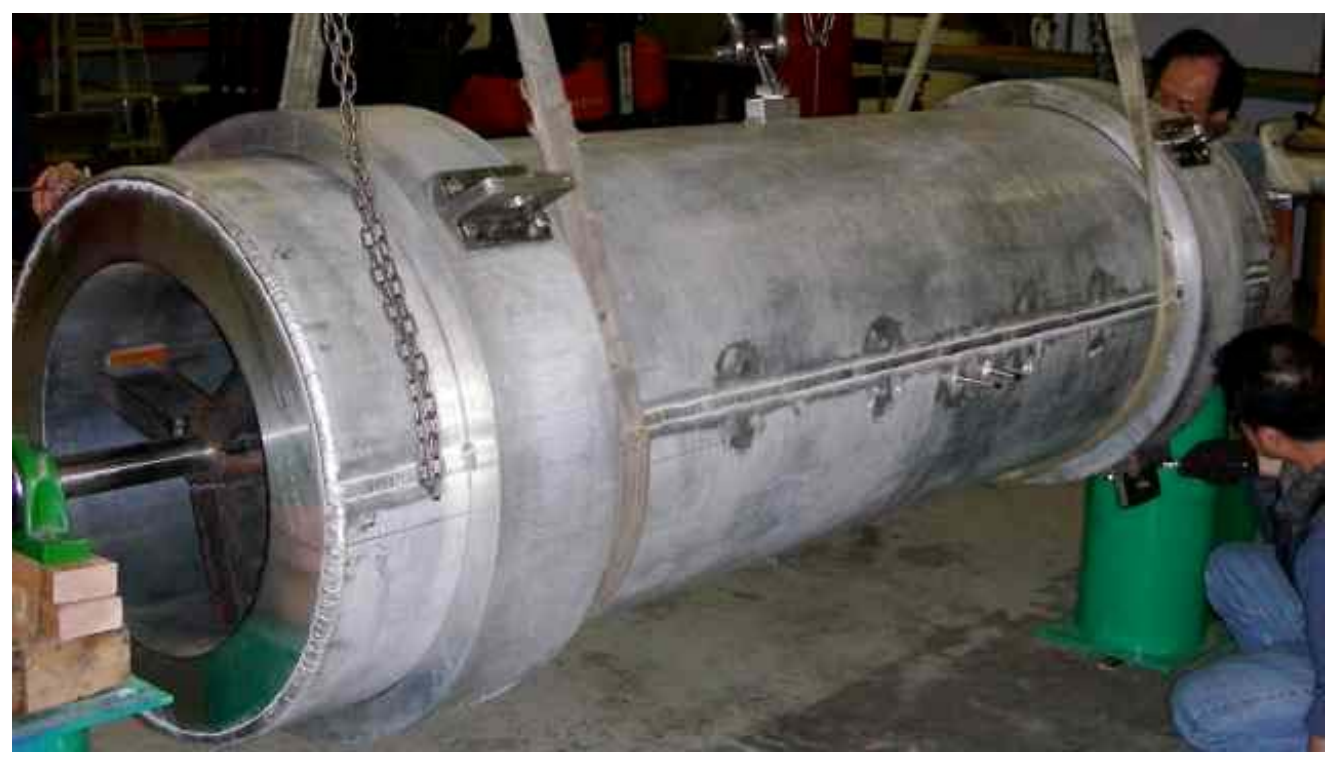

Figure 4. The Cold Mass of Magnet 1 after the Outer Shell has been installed and welded 
Table 5. The As Built Dimensions and Turns for Tracker Solenoid Number 2

\begin{tabular}{lccccc}
\hline \hline Parameter & Match 1 & Match 2 & End 1 & Center & End 2 \\
\hline Inner Coil Radius (mm) & 258 & 258 & 258 & 258 & 258 \\
Coil Thickness (mm) & 46.165 & 30.925 & 60.905 & 22.125 & 67.783 \\
Coil Length (mm) & 201.268 & 199.492 & 110.642 & 1314.30 & 110.642 \\
Current Center Axial Position* (mm) & 124.00 & 564.00 & 964.00 & 1714.00 & 2464.00 \\
Current Center Radial Position* (mm) & 281.083 & 273.463 & 288.453 & 269.063 & 291.891 \\
Coil Average J (A mm ${ }^{-2}$ ) & 137.67 & 147.77 & 124.28 & 147.66 & 127.09 \\
Number of layers per Coil & 42 & 28 & 56 & 20 & 62 \\
Number of Turns per Layer & 115 & 114 & 64 & 768 & 64 \\
Total Number of Turns & 4830 & 3192 & 3584 & 15360 & 3968 \\
Design Current (A)** & 264.83 & 285.60 & 233.68 & 275.52 & 240.21 \\
Coil Self Inductance (H)^ & 12.0 & 5.0 & 9.0 & 40.0 & 11.3 \\
Coil Stored Energy (MJ)** & 0.42 & 0.20 & 0.26 & 1.55 & 0.32 \\
Peak Field in Coil (T)** & 5.30 & 4.32 & 5.68 & 4.24 & 5.86 \\
Temperature Margin at 4.2 K (K)** & $\sim 1.6$ & $\sim 1.8$ & $\sim 1.5$ & $\sim 2.0$ & $\sim 1.5$ \\
\hline
\end{tabular}

* Based on $\mathrm{Z}=0$ is at the match coil end of the magnet cold mass. (The center of MICE in these coordinates is at $\mathrm{Z}=-3487 \mathrm{~mm}$.) $\mathrm{R}=0$ is the axis of the magnet (the MICE axis).

** This is at the maximum design current, which is based on the worst-case currents for the five coils.

$\wedge$ The inductance of the two end coils and the center coil in series is about $74 \mathrm{H}$.

Table 6. Changes in As Built Dimensions and Turns for Tracker Solenoid Number 2 Compared to the Magnet Design

\begin{tabular}{lccccc}
\hline \hline Parameter & Match 1 & Match 2 & End 1 & Center & End 2 \\
\hline Inner Coil Radius (mm) & $< \pm 0.05$ & $< \pm 0.05$ & $< \pm 0.05$ & $< \pm 0.05$ & $< \pm 0.05$ \\
Coil Thickness (mm) & +1.565 & +1.125 & +1.305 & +0.825 & +3.883 \\
Coil Length (mm) & 0.068 & -0.008 & +0.042 & $-0-$ & +0.042 \\
Current Center Axial Position* (mm) & \pm 0.05 & \pm 0.05 & \pm 0.05 & \pm 0.05 & \pm 0.05 \\
Current Center Radial Position* (mm) & +0.783 & +0.551 & +0.653 & +0.413 & +1.942 \\
Coil Average J (A mm ${ }^{-2}$ ) & -4.52 & -4.85 & -2.77 & -5.72 & -14.86 \\
Number of layers per Coil & 0 & 0 & 0 & 0 & 2 \\
Number of Turns per Layer & -5 & -5 & -2 & -16 & -2 \\
Total Number of Turns & -210 & -140 & -188 & -320 & +8 \\
Design Current (A)* & +11.03 & +12.00 & +7.08 & +5.62 & -0.49 \\
Coil Self Inductance (H) & -1.0 & -0.4 & -0.5 & -1.5 & +0.2 \\
Coil Stored Energy (MJ)* & $\sim 0.00$ & $\sim 0.00$ & $\sim 0.00$ & $\sim+0.01$ & $\sim 0.00$ \\
Peak Field in Coil (T)* & $\sim 0.0$ & $\sim 0.0$ & $\sim 0.0$ & $\sim 0.0$ & $\sim 0.0$ \\
Temperature Margin at 4.2 K (K)* & $\sim-0.1$ & $\sim-0.1$ & $\sim-0.1$ & $\sim 0.0$ & $\sim 0.0$ \\
\hline
\end{tabular}

* This change is at the coil maximum design current, which is based on the worst-case currents for the five coils.

$\wedge$ The change in inductance of the two end coils and the center coil in series is about $-3 \mathrm{H}$.

When on looks at Table 6, one can see that the inner radius of the coils in tracker magnet 2 is the same (within $\pm 50 \mu \mathrm{m}$ ) as the design proposed by the vendor. The design proposed by the vendor has a higher turns density than the vendor actually wound in the magnet. Each coil layer is thicker than anticipated and there are fewer turns per coil layer than anticipated. As a result, the magnet coils are thicker with fewer turns. 
The coil center in radial direction is larger by about 0.19 percent to 0.64 percent. The current center in the axial direction is accurate (with respect to the end of the cold mass) to about $\pm 0.05 \mathrm{~mm}$. The design current for all of coils, except for end coil 2 , is larger than the value called for in Table 2. The decision was made as with case of tracker magnet 1 to add two layers to end coil 2. Because the number turns per changed, the self-inductance of magnet coils changed accordingly. There is very little change in the magnet stored-energy, the coil peak field, and the coil temperature margin at $4.2 \mathrm{~K}$ between the magnet as built (Table 5) and the magnet as designed (Table 2).

\section{A Comparison of the Two Tracker Solenoids to Each Other}

Both tracker magnets as wound are different from the tracker magnet originally proposed by the magnet vendor. For the most part the differences between the as built magnet and the proposed magnet are small, so they can be accounted for by adjusting the currents in the coils of the two magnets.

It is proposed that the match coils 1 of the two magnets be connected in series. It is also proposed that match coils 2 of the two magnets be connected in series as well. It is also proposed that the spectrometer coil set (end coil 1, the center coil, and end coil 2) of tracker magnet 1 be in series with spectrometer coil set of tracker magnet 2 . If the corresponding coils of the two magnets can be connected in series, the number of 300 A power supplies is reduced from six to three. We propose to tune the two tracker magnets by using four $60 \mathrm{~A}$ power supplies across the end coils of the two spectrometer sets. As a result, one can ask the following questions, "Can the two tracker solenoids be connect in series as proposed? Can one reduce the number of tuning power supplies from four to two?" One can answer the two questions by comparing the two tracker magnets as they were built by the vendor. A direct comparison of tracker magnet 2 (Table 5) with tracker magnet 1 (Table 3) is shown in Table 7.

Table 7. A Comparison between Tracker Solenoid 2 and Tracker Solenoid 1 As-built

\begin{tabular}{|c|c|c|c|c|c|}
\hline Parameter & Match 1 & Match 2 & End 1 & Center & End 2 \\
\hline Inner Coil Radius (mm) & $< \pm 0.01$ & $< \pm 0.01$ & $< \pm 0.0$ & $< \pm 0.01$ & $< \pm 0.01$ \\
\hline Coil Thickness (mm) & -0.318 & +0.317 & -0.732 & -0.291 & -0.437 \\
\hline Coil Length (mm) & 0.068 & -0.008 & +0.042 & -0.001 & +0.042 \\
\hline Current Center Axial Position` ${ }^{\wedge}(\mathrm{mm})$ & \pm 0.05 & \pm 0.05 & \pm 0.05 & \pm 0.05 & \pm 0.05 \\
\hline Current Center Radial Position^ ${ }^{\wedge}(\mathrm{mm})$ & -0.159 & +0.159 & -0.366 & -0.145 & -0.219 \\
\hline Coil Average $\mathrm{J}\left(\mathrm{A} \mathrm{mm}^{-2}\right)$ & +0.94 & -1.53 & +1.47 & +1.92 & +0.81 \\
\hline Number of layers per Coil & 0 & 0 & 0 & 0 & 0 \\
\hline Number of Turns per Layer & 0 & 0 & 0 & -2 to 0 & 0 \\
\hline Total Number of Turns & 0 & 0 & 0 & +8 & 0 \\
\hline Design Current (A)* & \pm 0.01 & \pm 0.01 & \pm 0.01 & -0.15 & \pm 0.01 \\
\hline Coil Self Inductance (H) & $\sim 0$ & $\sim 0$ & $\sim 0$ & $\sim 0$ & $\sim 0$ \\
\hline Coil Stored Energy $(\mathrm{MJ})^{*}$ & $\sim 0.0$ & $\sim 0.0$ & $\sim 0.0$ & $\sim 0.0$ & $\sim 0.0$ \\
\hline Peak Field in Coil $(\mathrm{T})^{*}$ & $\sim 0$ & $\sim 0$ & $\sim 0$ & $\sim 0$ & $\sim 0$ \\
\hline Temperature Margin at $4.2 \mathrm{~K}(\mathrm{~K})^{*}$ & $\sim 0$ & $\sim 0$ & $\sim 0$ & $\sim 0$ & $\sim 0$ \\
\hline
\end{tabular}

$\wedge \quad$ The change in current position between the coils of the two magnets in the axial direction is with respect to the distance from end of the cold mass. The change in the position of the current center in the radial direction is with respect to the distance from axis of the solenoid.

* This change is at the coil maximum design current, which is based on the worst-case currents for the five coils. 
When one looks at Table 7, one sees that the longitudinal position of the coil current center is known to about 50 microns with respect to the cold mass. A 50-micron error in the longitudinal current center for the two magnet will be dominated by errors in placement of the coils in the cryostat, which are expected to be from $0.3 \mathrm{~mm}$ to $1.0 \mathrm{~mm}$. In general errors in the longitudinal current center position even $1 \mathrm{~mm}$ have no effect on the tuning of the MICE beam.

The current center in the radial direction is different for the respective coils for the two magnets. From Table 7, one can see that the difference between the magnets in the radial current center is $\pm 0.159 \mathrm{~mm}$ for both match coils. The radial current center error is 0.056 percent for the two match-coil ones. The radial current center error is 0.058 percent for the two match-coil twos. . From Table 7, one can see that the difference between the magnets in the radial current center is $-0.366 \mathrm{~mm}$ for end coil one. From Table 7 one can see that the difference between the magnets in the radial current center is $-0.219 \mathrm{~mm}$ for end coil two. The radial current center error is 0.127 percent for the two end-coil ones. The radial current center error is 0.075 percent for the two end-coil twos. When on looks at Table 7, one can see that the difference between the magnets in the radial current center is $-0.145 \mathrm{~mm}$ for the long center coil. The radial current center error is 0.054 percent for the two long center-coils. The differences in the radial current positions for corresponding coils in the two magnets varies from 0.054 percent to 0.127 percent.

It can be argued that radial position errors from 0.05 to 0.13 percent are small in the scheme of things. One can show that the overall effect of radial position errors is a second order effect. Discussions John Cobb and Holger Witt [1] in 2006 show that if one matches the field on axis closely with the ideal case, the MICE channel tune will remain good. The field generated along the axis (at $r=0$ ) of a single simple current loop [3] is as follows;

$$
B_{z}=\frac{\mu_{0} a^{2} I}{2\left(a^{2}+z^{2}\right)^{1.5}}
$$

where $\mathrm{a}$ is the radius of the current loop; $\mathrm{I}$ is the current in the loop; $\mu_{0}$ is the permeability of air $\left(\mu_{0}=4 \pi \times 10^{-7} \mathrm{H} \mathrm{m}^{-1}\right) . \mathrm{z}$ is the distance along the axis from the center of the current loop where the field is calculated. The on axis magnetic induction at $\mathrm{z}=0$ can be expressed as follows;

$$
B_{z}=0.5 \frac{\mu_{0} I}{a}
$$

From equation 2 , it is clear that the on axis induction at the center of the loop is proportional to one over the radius of the loop. Discussions with Ulisse Bravar [2] in 2004 suggest that the radial position of the current is not very important even though the magnetic field varies with radius. If one integrates equation 1 from $\mathrm{z}=-\infty$ to $\mathrm{z}=+\infty$, one gets the following result;

$$
\int_{z=-\infty}^{z=+\infty} B_{z} d z=\mu_{0} I
$$

When one looks at equation 3 , one sees that the integrated field along the magnet axis is independent of the radius of the loop. Effectively, the integrated field extends out from the current loop about one loop radius in each direction along the axis. From the standpoint of the beam, the magnitude of the integrated field is more important than the magnitude of the field. 
In simple terms, this is why the radial position of the current center has a second order effect on the muon beam in MICE. The short coils can be considered to be simple current loops. The long center coil of the tracker magnet can be considered to be a line of current loops. To first order the integrated field for the center coil is the sum of the loop integrated field. Thus the integrated field of the long coil is also independent of its radius.

The number of turns is identical for match coil 1 and match coil 2 for the two magnets. As a result, match coil 1 of the two magnets can be connected in series and match coil 2 of the two magnets can be connected in series. The number of turns is identical for end coil 1 and end coil 2 for the two magnets.

The center coil for tracker magnet 1 has eight fewer turns than the center coil of magnet 2 . The reason for this is that center coil of magnet 1 was the first coil wound by the vendor winding crew. The learning process on the coil winding occurred on the center coil of magnet 1. Virtually all of the turns differences occurred on the inner nine layers of the center coil of magnet 1. One layer had 766 turns; six layers had 767 turns; and the rest of the layers had 768 turns. All of the layers in the center coil of magnet 2 had 768 turns. If the magnets are connected in series, the total current carried by the center coil of magnet 2 is 0.052 percent higher than the total current in the center coil of magnet 1 . Unlike small changes in the current radius, the integrated field along the magnet axis will be different for the two center coils by 0.052 percent. As a result, the change in total current in the center coil will have a small effect on the beam when the two spectrometer solenoids (end coil 1, the center coil, and end coil 2) are connected in series. If one wants to balance the two center coils, one has to have a small power supply that puts $150 \mathrm{~mA}$ into the center coil of magnet 1 (at the full current needed to produce an induction of $4 \mathrm{~T}$ in the two trackers). It should be pointed out however that an error of 0.052 percent is much less than the allowable error for the field in the tracker. If one wants to make the correction of the current it is certainly possible to do so.

Because the end coils in the two magnets have the same number of turns, end coils 1 and end coils 2 can be connected in series using the 60 A tuning power supplies. In practical terms this means that there are two 60 A power supplies available for tuning the end coils of the focusing magnets at the ends of the cooling channel, should that be necessary.

\section{Errors in the Placement of the Two Cold Masses in their Vacuum Vessels}

The tracker magnet specification [4] calls for the following alignment provisions: 1) The tracker solenoid cold mass central axis shall be co-axial with the cryostat vacuum vessel axis within $\pm 300 \mu \mathrm{m}$ (0.012 inches). 2) The maximum allowable tilt of the cold mass axis (the magnetic axis) with respect to the axis of the warm bore tube shall be less than \pm 0.001 radian ( \pm 0.057 degree). If the specification is met, the axial position of each of the coils in the magnet shall be correct to $\pm 350 \mu \mathrm{m}(0.014$ inches $)$. If the first requirement in the specification is met, the tilt angle can be no larger than \pm 0.00033 radians $( \pm 0.019$ degrees). There are some who suggest that the co-axial standard of \pm 300 microns should be relaxed. Since the co-axial standard has direct bearing on the tilt standard, the coaxial standard should not be allowed to go above \pm 900 micron $(0.9 \mathrm{~mm}$ or 0.036 inches).

In the view of these authors and others, the tilt standard is far more important than the absolute standard for the position of the coil within the cryostat with respect to the magnet axis of the ends of the cryostat vacuum vessel. If the cryostat for the tracker solenoid must be adjusted with respect to MICE it can be. Tilt may be harder to adjust for than absolute position. 
Figures 5 and 6 show the assembly of the tracker solenoid into the solenoid vacuum vessel. The solenoid vacuum vessel is a roll up and it isn't very round. The cold mass, when it is mounted in the cold mass must be approximately co-axial with the vacuum vessel. The axis of the cold mass must be parallel to the plane formed by the stand legs within 350 microns. The axis of the cold mass forms the axis of the room temperature bore tube. Figure 7 shows the solenoid with its end plates in place. The final fully assembled tracker magnet 1 with its coolers in place is shown in Figure 8.

The final position of tracker solenoid 1 was supposed to be correct to the end plates within $\pm 0.5 \mathrm{~mm}$, but a mistake was made and the end plates were reversed during the final grinding step. The axis of the warm bore tube is correct within $\pm 1 \mathrm{~mm}$. In the second tracker magnet, we expect the axis to be correct within $\pm 0.5 \mathrm{~mm}$. If the axis of the cold mass and the axis of the warm bore tube are correct to within $\pm 0.5 \mathrm{~mm}$, the magnetic axis tilt angle with respect to the physical axis of the warm bore tube will be less than \pm 0.00055 radian. If the axis placement errors are $\pm 1 \mathrm{~mm}$, the tilt angle error can be as large as \pm 0.0011 radian. The tilt angle will be verified by the magnetic measurements done at Fermilab.

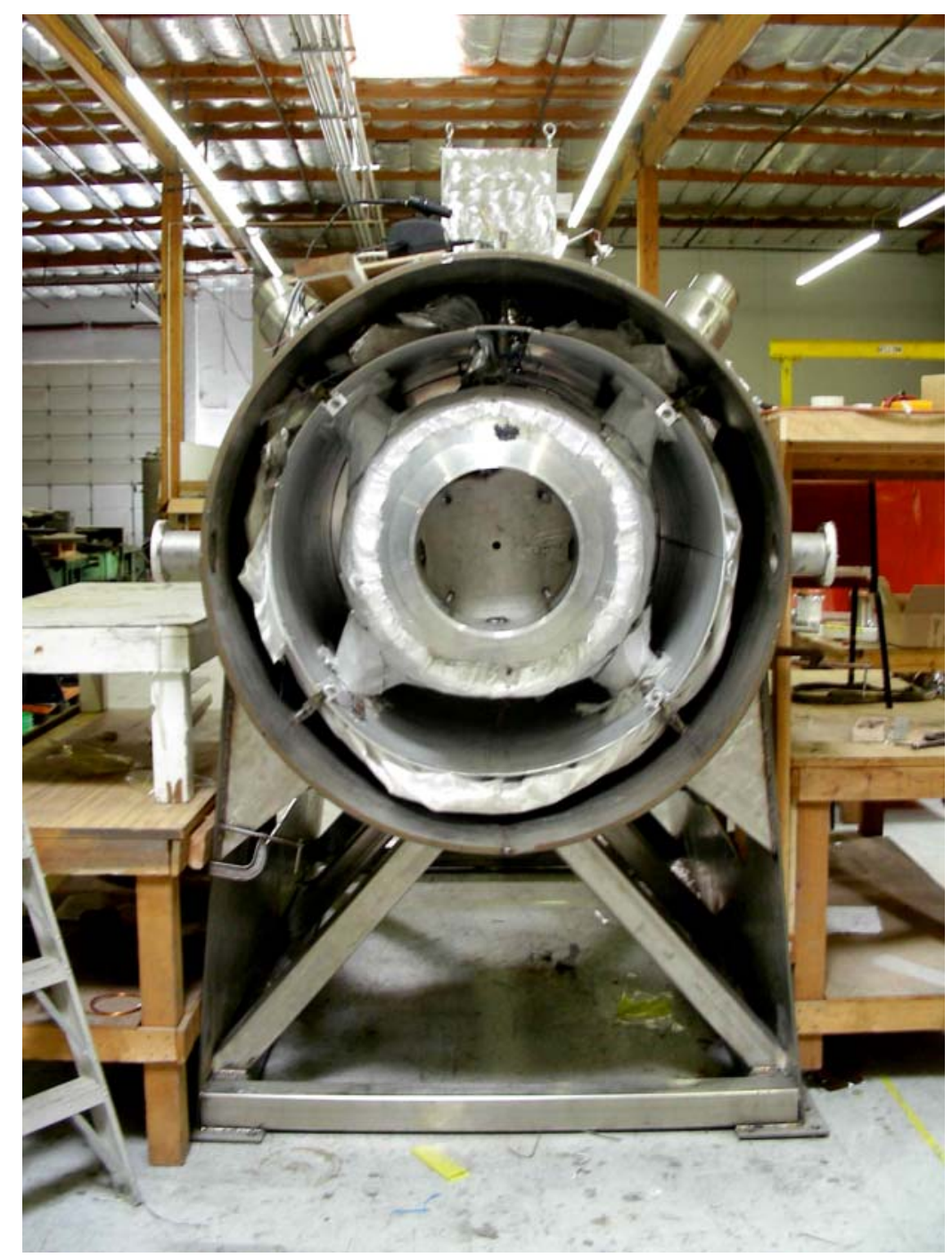

Figure 5. The Assembly of the Cold Mass and the Cylindrical $70 \mathrm{~K}$ Shield within the Cryostat Vacuum Vessel 


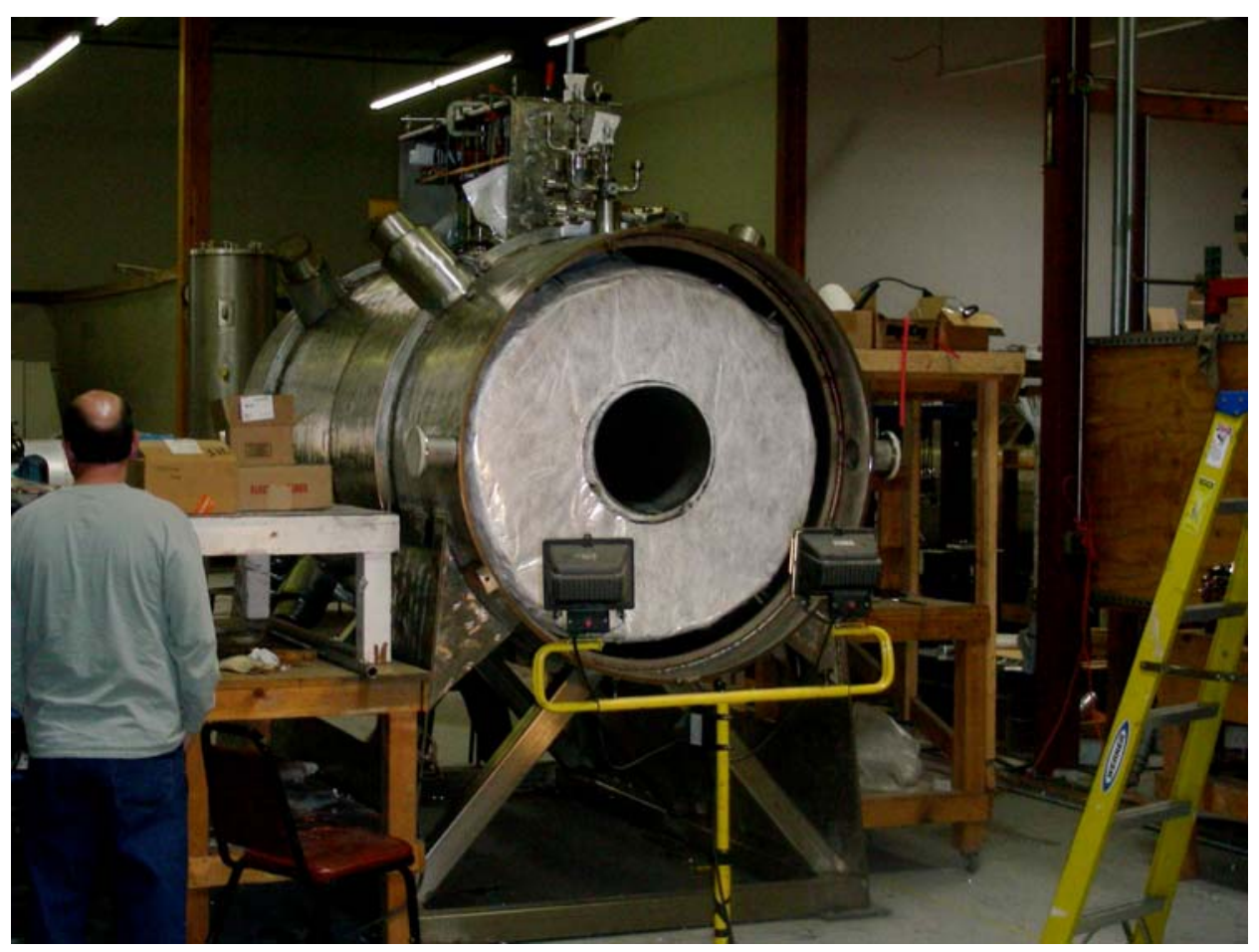

Figure 6. The Assembly of the Stack and the Vacuum Vessel before the End Plates were Installed

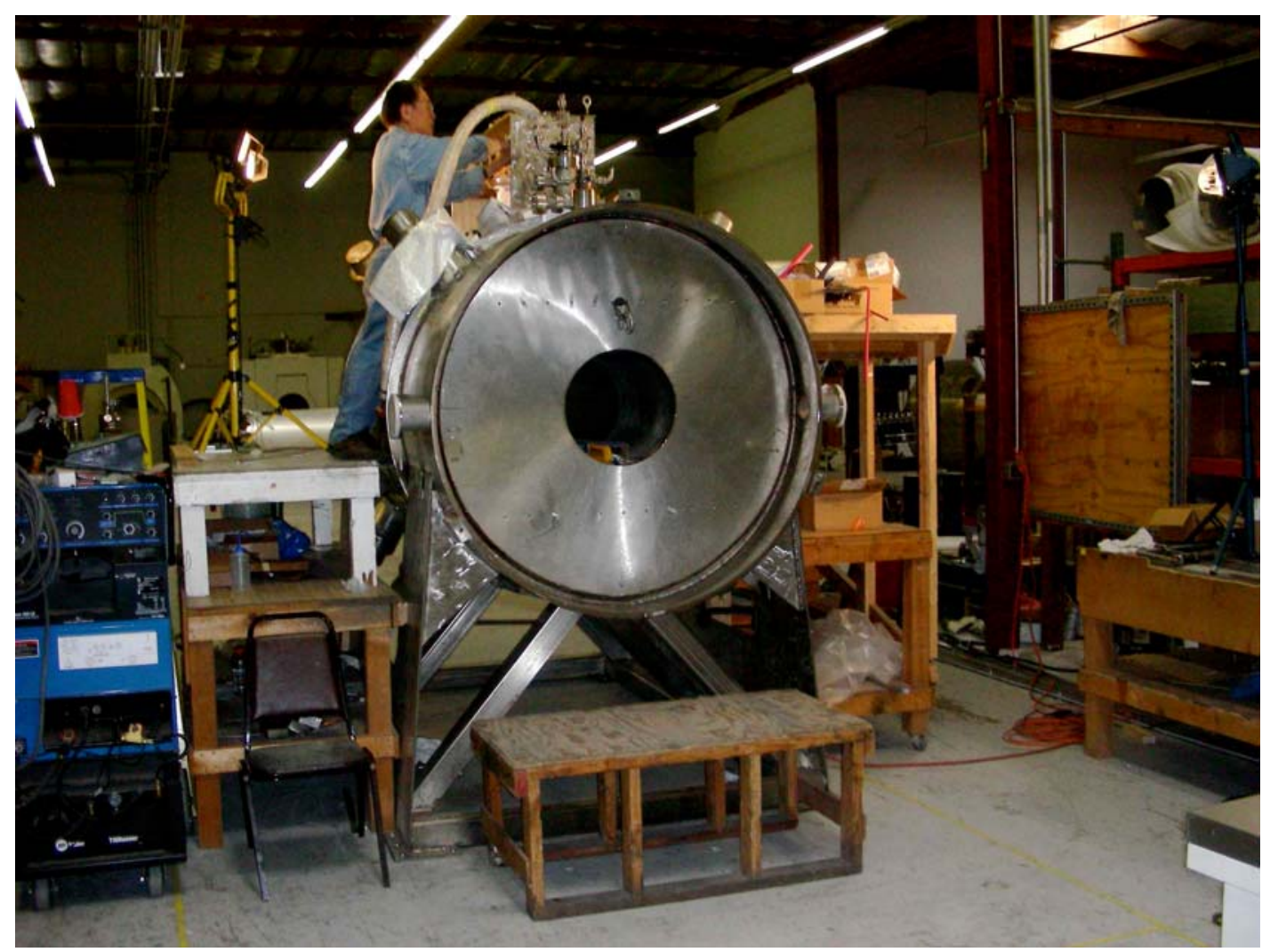

Figure 7. The Tracker Solenoid with End Plates in Place (The assembly of the leads and tower is not finished.) 


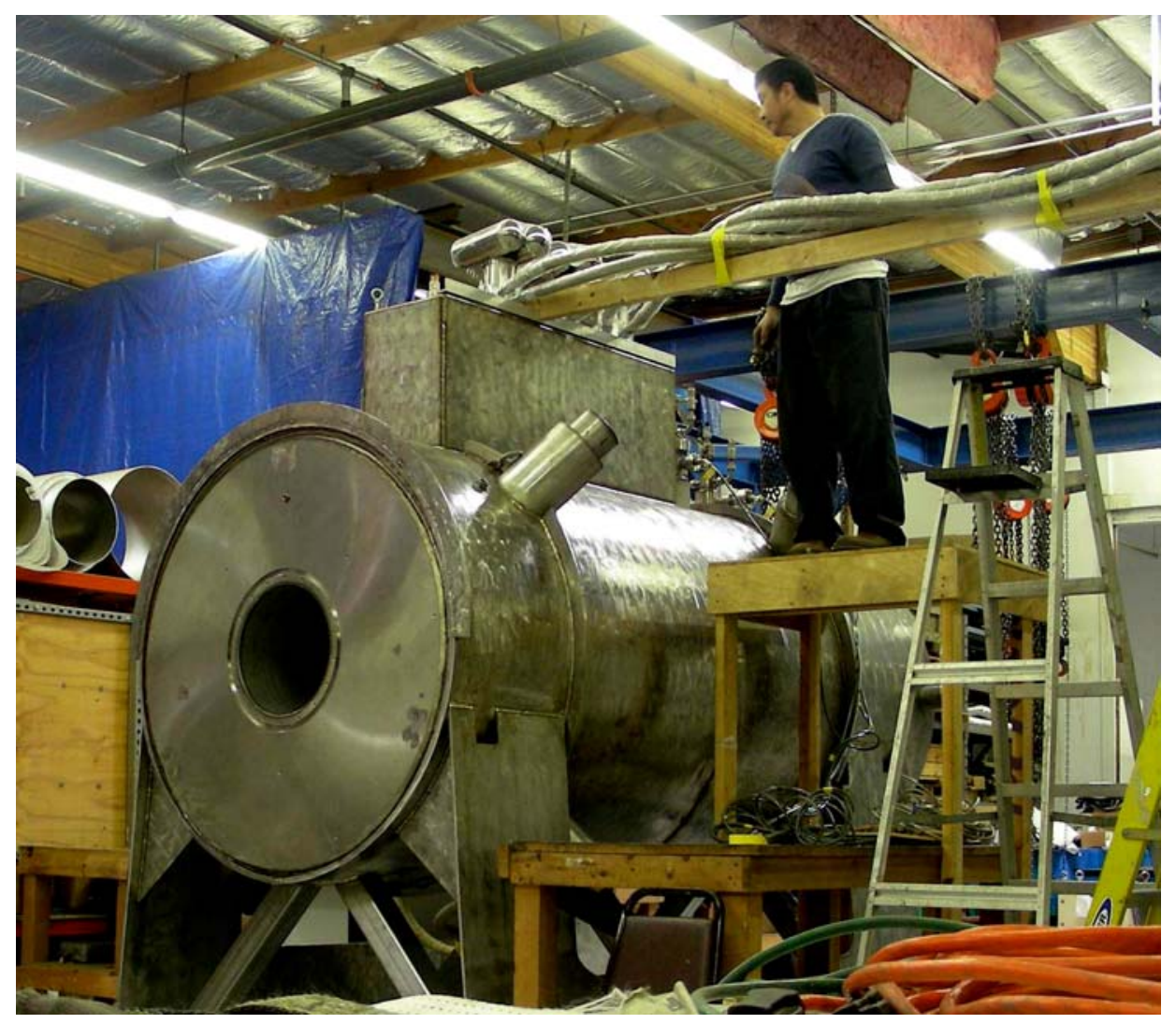

Figure 8. The Finished Tracker Magnet 1 with Three PT-415 Coolers Installed

\section{Some Concluding Comments}

The two tracker solenoid magnets appear to be nearly identical. The match coils two tracker magnets have the same number of turns. The end coils for the spectrometer section of the two tracker magnets have the same number of turns. The long center coil in the spectrometer section of magnet 2 has eight more turns than magnet number 1 . This means that the field in tracker region of magnet 2 will be 0.058 percent larger than the field in magnet number 1 . If needed, the center coil of magnet 1 could have a power supply that supplies $0.15 \mathrm{~A}$. All of the coils in magnet 1 can be connected in series with the coils in magnet 2 .

The current centers in the axial direction are correct to $\pm 0.05 \mathrm{~mm}$ within each cold mass. The axial position of each of the cold mass appears to be correct within the vacuum vessel to about $\pm 0.5 \mathrm{~mm}$. The difference radial position of the current centers with in the magnet cold masses varies from 0.145 to $0.366 \mathrm{~mm}$ ( 0.053 to 0.127 percent). This has a second order effect on the beam going through the solenoid. The radial position of the cold mass with respect to the warm bore tube should be within $\pm 1 \mathrm{~mm}$ for tracker magnet 1 . The tilt angle of the cold mass axis with respect to the warm bore axis will be about \pm 0.001 radian for this magnet. In tracker magnet 2, we expect the radial position of the warm bore axis to be with $\pm 0.5 \mathrm{~mm}$ of the correct position. The warm bore axis tilt angle error should be less than \pm 0.001 radian.

In general, there have been more problems with the fabrication of magnet 1 than we expect there will be with magnet 2 . We expect magnet 2 to be close to the original specification. The positional errors in magnet 1 are about two times what is required by the original specification. 


\section{Acknowledgements}

The tracker magnets shown in this report were wound and fabricated by Wang NMR incorporated in Livermore CA. The authors thank Wang NMR for the information needed to write this report. This work was also supported by the Office of Science, United States Department of Energy, under DOE contract DE-AC02-05CH11231. DOE funding for the US Neutrino Factory and Muon Collider Collaboration is also gratefully acknowledged.

\section{References}

[1] G. Gregoire, G. Ryckewaert, L. et al, "MICE and International Muon Ionization Cooling Experiment Technical Reference Document," http:/hep04.phys.iit.edu/cooldemo/notes (October 2004)

[2] M. A. Green, "The Superconducting Solenoids for the MICE," LBNL Report LBNL-51920, December. 2002, MICE Note 58

[3] P. Fabbricatore, S. Farinon, U. Bravar, and M. A. Green, "The Mechanical and Thermal Design for the MICE Detector Solenoid Magnet System," IEEE Transactions on Applied Superconductivity 15, No. 2, p 1255, (2005), LBNL-57376, MICE Note 110

[4] M. A. Green, C. Y. Chen, T. Juang W. Lau, C. Taylor, S. P. Virostek, R. Wahrer, S. T. Wang, H. Witte, and S. Q. Yang, "Design Parameters for the MICE Tracker Solenoid," IEEE Transactions on Applied Superconductivity 17, No. 2, p 1247, (2007), LBNL-61383, MICE Note 158

[5] M. A. Green and S. P. Virostek, "Technical Specification for MICE Spectrometer Solenoid Magnets, Fabrication, Assembly, Test and Shipping," LBNL Specification 10154, 23 March 2006

[6] LBNL-MICE Superconductor Specification for Nb-Ti Superconducting Wire for the MICE Solenoids, 25 October 2005 


\section{DISCLAIMER}

This document was prepared as an account of work sponsored by the United States Government. While this document is believed to contain correct information, neither the United States Government nor any agency thereof, nor The Regents of the University of California, nor any of their employees, makes any warranty, express or implied, or assumes any legal responsibility for the accuracy, completeness, or usefulness of any information, apparatus, product, or process disclosed, or represents that its use would not infringe privately owned rights. Reference herein to any specific commercial product, process, or service by its trade name, trademark, manufacturer, or otherwise, does not necessarily constitute or imply its endorsement, recommendation, or favoring by the United States Government or any agency thereof, or The Regents of the University of California. The views and opinions of authors expressed herein do not necessarily state or reflect those of the United States Government or any agency thereof, or The Regents of the University of California. 